\title{
Simultaneous improvement of surface quality and productivity using grey relational analysis based Taguchi design for turning couple (AISI D3 steel/ mixed ceramic tool $\left.\left(\mathrm{Al}_{2} \mathrm{O}_{3}+\mathrm{TiC}\right)\right)$
}

\author{
Oussama Zerti ${ }^{*}$, Mohamed Athmane Yallese ${ }^{\mathrm{a}}$, Abderrahmen Zerti ${ }^{\mathrm{a}}$, Salim Belhadi ${ }^{\mathrm{a}}$ and Francois \\ Girardin $^{b}$
}

${ }^{a}$ Mechanics and Structures Research Laboratory (LMS), Mechanical Engineering Dept., May 8th 1945 University, Guelma 24000, Algeria ${ }^{b}$ Laboratoire Vibrations Acoustique, INSA-Lyon, 25 bis avenue Jean Capelle, F-69621 Villeurbanne Cedex, France

\section{CH R O N I C L E}

\section{Article history:}

Received June 22017

Received in Revised Format July 12017

Accepted July 162017

Available online

July 162017

Keywords:

Simultaneous improvement

GRA

Taguchi design

S/N ratio

ANOVA

AISI D3 Steel

Ceramic

\section{A B S T R A C T}

Current optimization strategies are based on the increase the productivity and the quality with lower cost in short time. Grey relational analysis "GRA" based on Taguchi design was proposed in this paper for simultaneous improvement of surface quality and productivity. The turning trials based on mixed Taguchi L18 factorial plan were conducted under dry cutting conditions for the machining couple: AISI D3 steel/mixed ceramic inserts (CC650). The machining parameters taken into account during this study are as follow: major cutting edge angle $(\chi \mathrm{r})$, cutting insert nose radius (r), cutting speed (Vc), feed rate (f), and depth of cut (ap). Significant effects of machining parameters and their interactions were evaluated by the analysis of variance. Through this analysis, it have been found clearly that feed rate and cutting insert nose radius had a big significant effects on surface quality while depth of cut, feed rate followed by cutting speed had a major effect on productivity. The mathematical relationship between the machining parameters and the performance characteristics was formulated by using a linear regression model with interactions. Optimal levels of parametric combination for achieving the higher surface quality with maximum productivity were selected by grey relational analysis which is based on the high value of grey relational grade. Confirmation experiments were carried out to prove the powerful improvement of experimental results and to validate the effectiveness of the multi-optimization technique applied in this paper.

\section{Nomenclature}

\begin{tabular}{|c|c|c|c|}
\hline ANOVA & Analysis of variance & $\mathrm{OA}$ & Orthogonal array \\
\hline$a p$ & Depth of cut (mm) & $R a$ & Arithmetic mean roughness $(\mu \mathrm{m})$ \\
\hline Cont $\%$ & Contribution ratio $(\%)$ & $r$ & Nose radius of cutting insert (mm) \\
\hline DF & Degrees of freedom & RSM & Response surface methodology \\
\hline$f$ & Feed rate $(\mathrm{mm} / \mathrm{rev})$ & SS & Sum of squares \\
\hline GRA & Grey relational analysis & $\mathrm{S} / \mathrm{N}$ & Signal-to-noise ratio \\
\hline GRC & Grey relational coefficient & $V_{c}$ & Cutting speed (m/min) \\
\hline GRG & Grey relational grade & $\alpha$ & Clearance angle (degree) \\
\hline MS & Mean squares & $\gamma$ & Rake angle (degree) \\
\hline$M R R$ & Material removal rate $\left(\mathrm{mm}^{3} / \mathrm{min}\right)$ & $\lambda$ & Inclination angle (degree) \\
\hline$\chi r$ & Major cutting edge angle (degree) & & \\
\hline
\end{tabular}




\section{Introduction}

Surface roughness represents an evaluation criterion of quality products and it plays an important role to estimate the manufacturing cost (Asiltürk \& Akkus, 2011; Zerti et al., 2017a,b). On the other hand, the productivity is considered as a very important technological aspect that causes great effect on both product cost and series production rate (Hassan et al., 2012). For this reason, manufacturers are always committed by the good quality and high productivity in short time with low cost, because ensuring those conditions represent an index of manufacturer's qualification. Consequently, the desired surface quality with the maximum productivity is a major constraint for the choice of the optimum machining parameters in the production process. In order to achieve the desired conditions required by customers, the use of grey relational analysis as a multi-objective optimization technique based on Taguchi design is found as an efficient solution for this optimization problem. This technique has been used in different applications in because of its ease of application and reliability.

There are a number of researchers in different fields who have used grey relational analysis based on Taguchi design for a simultaneous improvement of multi-performance characteristics in order to achieve at the desired objective.

Bouzid et al. (2014) optimized cutting parameters for determining the minimum surface roughness (Ra) which corresponds to the maximum material removal rate (MRR) in turning of X20Cr13 steel with mono and multi-objective optimizations based on the L16 OA of Taguchi. Taguchi's signal-to-noise ratio was used to accomplish the objective function. Wang and Lan (2008) selected the optimum cutting conditions through the application of grey relational analysis based on Taguchi design $\left(\mathrm{L}_{9} \mathrm{OA}\right)$ with introducing of signal to noise ratio $(\mathrm{S} / \mathrm{N})$ to get the lowest surface roughness and tool wear that correspond to the maximum of material removal rate in precision turning.

Lin (2004) reported an improvement of tool life, cutting force, and surface roughness by using Taguchi method with grey relational analysis for optimizing cutting speed, feed rate, and depth of cut during turning operations of S45C steel bars using a P20 tungsten carbide. They found that optimization of complicated multiple performance characteristics could be greatly simplified through this approach. Balasubramanian and Ganapathy (2011) solved the problem of simultaneous optimization for wire electro discharge machining (WEDM) to obtain higher material removal rate (MRR) and lower surface roughness (SR) by the use of grey relational analysis.

Hanafi et al. (2012) applied the method of grey relational analysis based on the Taguchi method for multiobjective optimization of power consumption and surface roughness when dry turning of the PEEK reinforced with $30 \%$ carbon fibers. The same technique was proposed in other several cutting process, for example: in the drilling process Noorul Haq et al. (2008) identified optimal drilling parameters namely: cutting speed, feed rate and point angle for multiple response characteristics such as surface roughness, cutting force and torque in the case of machining couple: $\mathrm{Al} / \mathrm{SiC}$ metal matrix composite/TiN coated HSS twist drills under dry condition. The authors found that this technique is so reliable for improving the drilling process.

For another type of cutting process, Kuram and Ozcelik (2013) performed an experimental investigation based on the L9 OA of Taguchi method for Micro-milling of aluminium material with ball nose end mill. The authors applied Taguchi method and grey relational analysis to achieve at mono and multi-objective optimization. The works accomplished by Jailani et al. (2009) aimed to use grey relational analysis in order to optimize the sintering process parameters of Al-Si (12\%) alloy/fly ash composite. The modelling of the cutting process has attracted the attention of many researchers for its great interest in the industry because it allows predicting the technological parameters without carrying out the experimental tests. An attempt was made by Gaitonde et al. (2009) to determine the link between cutting condition such as cutting speed, feed rate, and machining time and machinability aspects via response surface methodology. These considered aspects were machining force, power, specific cutting force, surface 
roughness, and tool wear. The study was carried out for the case of turning of high chromium AISI D2 cold work tool steel using CC650WG wiper ceramic inserts. Authors found through the response surface analysis that the surface roughness could be minimized at small values of feed rate and machining time with elevated values of cutting speed, whereas the maximum tool wear appear at $\mathrm{Vc}=150 \mathrm{~m} / \mathrm{min}$ for all values of feed rate.

Al-Ahmari (2007) formulated mathematical equations of surface roughness and cutting forces during turning of austenitic AISI 302 steel. The process parameters considered in this study were cutting speed, feed rate, depth of cut and nose radius in order to develop a machinability model. Additionally, response surface methodology (RSM) and neural networks (NN) were employed to assess the model. Zahia et al. (2015) exploited the RSM methodology that helps to formulate a reliable statistical model for monitoring the evolution of surface roughness and cutting forces according to cutting parameters such as: cutting speed, feed rate and depth of cut during the hard turning (AISI 4140) (56 HRC) with using PVD - coated ceramic insert. Zahia et al. (2013) developed a mathematical model of surface roughness that vary in function of cutting parameters, tool-nose displacements, spindle and machine tool frame. The study of Neseli et al. (2011) presented an application of response surface methodology (RSM) for modeling the average surface roughness ( $\mathrm{Ra}$ ) obtained during the turning of AISI 1040 steel, to assess the effect of tool geometry parameters on the latter. They found that the tool nose radius was the most influencing factor on the measured surface roughness.

Ceramic cutting tool is a big utilization in the machining of high alloy steel, Davim and Figueira (2007a) made a comparison between the wiper and conventional ceramics inserts to determine the influences of cutting parameters on the obtained machinability parameters (cutting forces, surface roughness, and tool wear). They found after that the use of wiper ceramics inserts allow to reach at surface roughness values less than $0.8 \mu \mathrm{m}$ with possibility of dimensional accuracy in a work-piece, IT $<7$.

Davim and Figueira (2007b) used ceramic inserts for surface finishing phase on the same material (cold work tool steel AISI D2). They revealed that obtaining surface roughness of less than $0.8 \mu \mathrm{m}$ is feasible if the choice of cutting parameters is suitable and which also permit to eliminate cylindrical grinding operations. Aouici et al. (2014) examined the machinability behavior of cold work hard tool steel AISI D3 heat-treated (60 HRC) with a TiN doped ceramic cutting tool (SNGA120408) containing approximately $30 \%$ of $\mathrm{TiC}$. The responses were estimated based on a $\left(3^{3}\right)$ full factorial experimental design, where the quadratic effects were also determined. The desired optimum was set for minimum levels of surface roughness, cutting force, specific cutting force and consumed power via the statistical method (RSM) and the desirability function approach.

Singh and Dureja (2014) compared Taguchi method and RSM with a view for optimizing flank wear of tool and surface roughness during the finish operation of AISI D3 steel in hard turning. The results indicated that optimal levels of cutting parameters selected by both RSM and Taguchi method were nearly the same. Zerti et al. (2017) proposed a study with the application of Taguchi method to minimize some technological parameters (such as surface roughness, tangential force, specific cutting force, and cutting power) characterizing material machinability. They carried out 18 tests based on Taguchi design experiments during the turning of AISI D3 steel using mixed ceramic inserts (CC650) under dry cutting conditions. Bouchelaghem et al. (2010) examined the machinability behavior of AISI D3 hardened steel with CBN cutting tool for the evolution of surface roughness, cutting forces and tool wear in function of variation of cutting parameters. Bensouilah et al. (2016) conducted a comparative study to evaluate the performance of coated and uncoated mixed ceramic tools during hard turning of AISI D3 cold work tool steel. They determined the effects of cutting parameters on the machining performance through the use of ANOVA analysis of $\mathrm{S} / \mathrm{N}$ ratio of the responses. The authors modeled the machining performance by linear regression for both ceramic tools CC6050 and CC650. Yallese et al. (2005) evaluated the effect of cutting parameters during the hard turning of AISI D3 steel with ceramic and CBN tool wear. They estimated the surface roughness by a power model deduced from experimental data and compared it with 
a theoretical model. Meddour et al. (2015) performed a statistical study to determine the significant effect of cutting speed, depth of cut, feed rate and tool nose radius on surface roughness and components of cutting force during hard turning of AISI 52100 steel by mixed ceramic cutting tool. They developed mathematical models in order to estimate those two responses. Also, they recommended that the use of big nose radius and little feed rates could improve surface quality.

The present research paper shows an experimental investigation related to the simultaneous improvement of surface quality (Ra) and productivity (MRR) using the application of grey relational analysis (GRA) based on Taguchi design (L18 OA) during the dry turning of (AISI D3 steel/ mixed ceramic inserts). Response Surface Methodology (RSM) was exploited to obtain an empiric mathematical models by regression analysis for the surface roughness and material removal rate. The ANOVA analysis of S/N ratio described the degree of influence of each of the control machining parameters and their interactions on each response. Also Pareto chart and 3D plots with their contours based on $\mathrm{S} / \mathrm{N}$ ratios of responses were used to confirm the results found by ANOVA analysis. 3D surface roughness profile was made to view visualizing its topography. Confirmation tests were carried out to ensure the effectiveness of the grey relational analysis based on Taguchi design in the simultaneous improvement of the performance characteristics considered in this study.

\section{Taguchi design / Grey Relational Analysis (GRA)}

\subsection{Taguchi design}

Taguchi design is a helpful technique that has a big contribution for the improvement of the performance of systems and solving complex optimization problems (settings) during production of the product by the implementation of the design experiments that is based on the use of the orthogonal arrays which are proposed by Taguchi for minimizing the number of trials and focusing just on the essential experiments for analyzing, which lead to win the time and reducing the cost Taguchi (1986). Also this method allows controlling simultaneously controllable and uncontrollable factors by converting the responses into signal-to-noise $(\mathrm{S} / \mathrm{N})$ for identifying industrial performance of the system Zhang et al. (2007). S/N ratio is the essential criterion in the Taguchi method, it allows defining the degree of influence of the unwanted noise on the wanted signal Günay et al. (2011). Whenever the characteristic is continuous, the $\mathrm{S} / \mathrm{N}$ ratios are usually divided into 3 categories given by the following equations Nalbant et al. (2007):

For (Nominal is the best): $S / N=10 \log \left(\frac{\bar{y}}{S_{y}^{2}}\right)$

For maximization (Larger-is-the better): $S / N=-10 \log \left(\frac{1}{n} \sum_{i=1}^{n} \frac{1}{y_{i}^{2}}\right)$

For minimization (Smaller-is-the better): $S / N=-10 \log \left(\frac{1}{n} \sum_{i=1}^{n} y_{i}^{2}\right)$

where $\bar{y}$ is the average of results obtained, $S_{y}^{2}$ is the variance of $y, n$ is the number of repeat trials and $\mathrm{y}_{\mathrm{i}}$ is the result obtained.

\subsection{Grey Relational Analysis (GRA)}

Grey relational analysis is a technique proposed for solving the problem of complex optimization by converting the multi-objective to a single-objective to achieve at optimal combination of parameters levels for simultaneous improvement of multiple machining characteristics Dabade (2013). The use of this method contains the steps as follow: 
Step 1: Grey relational generation

According to the intended objective optimization to minimize or maximize experimental results, normalization of $\mathrm{S} / \mathrm{N}$ ratio for the experimental results in the range between zero and one is necessary for grey relational generation. Depending on the objective function optimization, the normalization can be performed for two cases. If the smaller-the-better is the characteristic selected in the original sequence for minimization, then it should be normalized as given by Eq. (4).

$$
x_{i}^{*}(k)=\frac{\max \left(x_{i}^{0}(k)\right)-x_{i}^{0}(k)}{\max \left(x_{i}^{0}(k)\right)-\min \left(x_{i}^{0}(k)\right)}
$$

If the larger-the-better is the characteristic selected in the original sequence for maximization, then it should be normalized as given by Eq. (5).

$$
x_{i}^{*}(k)=\frac{x_{i}^{0}(k)-\min \left(x_{i}^{0}(k)\right)}{\max \left(x_{i}^{0}(k)\right)-\min \left(x_{i}^{0}(k)\right)}
$$

where $x_{i}^{*}(k)$ is the value after grey relational generation (normalized value), and $\max \left(x_{i}{ }^{0}(k)\right)$ and $\min \left(x_{i}{ }^{0}(k)\right)$ are the largest and smallest values of $\left.x_{i}{ }^{0}(k)\right)$ for the $\mathrm{k}^{\text {th }}$ response. The larger value of normalized results indicates the better performance characteristic and the best-normalized results will be equal to one.

\section{Step 2: Grey Relational Coefficient (GRC)}

Grey relational coefficient describes the correlation between the ideal and the obtained experimental results. Mathematical formula of grey relational coefficient $\left(\xi_{\mathrm{i}}(\mathrm{k})\right)$ is given as following:

$$
\begin{aligned}
& \xi_{i}(k)=\frac{\Delta_{\min }+\psi \Delta_{\max }}{\Delta_{0 i}(k)+\psi \Delta_{\max }} \\
& 0<\xi_{i}(k) \leq 1
\end{aligned}
$$

$\Delta_{0 i}(k)$ is the absolute difference between the reference sequence $x_{0}^{k}(k)$ and the $\mathrm{S} / \mathrm{N}$ ratio of measured sequence $x_{i}^{k}(k)$.

$$
\begin{aligned}
& \Delta_{0 i}(k)=\left\|x_{0}(k)-x_{i}(k)\right\| \\
& \Delta_{\min }=\min _{\forall j \in i} \min _{\forall k}\left\|x_{0}(k)-x_{i}(k)\right\| \\
& \Delta_{\max }=\max _{\forall j \in i} \max _{\forall k}\left\|x_{0}(k)-x_{i}(k)\right\|
\end{aligned}
$$

$\psi$ is the distinguishing coefficient $(\psi \in[0,1])$. In this study the value of $\psi$ is 0.5 .

\section{Step 3: Grey Relational Grade (GRG)}

Grey relational grade represents the correlation among the series, it is given by the following formula:

$$
\alpha_{i}=\frac{1}{n} \sum_{k=1}^{n} \xi_{i}(k)
$$

where $n$ is the number of responses. 
Step 4: Determination of optimal machining parameters

Once grey relational grade is computed, the selection of the optimal levels combination is made based on the main effects plot for (GRG). The largest value of grey relational grade that is found close to the ideal normalized value corresponds to the optimal combination. Therefore, the optimal level of the process parameters is the level with the greatest GRG value.

Step 5: Confirmation tests

Once the optimal levels are selected, the validation test occupied the final step in the optimization procedure to confirm the reliability of the optimal levels is proposed by grey relational analysis to improve system performance. This test is done by comparing the value of the $\mathrm{S} / \mathrm{N}$ ratio of GRG obtained from the optimal test with that predicted $\hat{\eta}$ by the following formula with the use of optimal levels (Nalbant et al., 2007):

$$
\hat{\eta}=\eta_{m}+\sum_{i=1}^{q}\left(\bar{\eta}_{i}-\eta_{m}\right)
$$

where $\eta_{m}$ is the total average of $\mathrm{S} / \mathrm{N}$ ratio, $\bar{\eta}_{i}$ is the average of $\mathrm{S} / \mathrm{N}$ ratio at the optimal level, and $q$ is the number of the main input factors that have a significant effect on the output responses.

\subsection{Grey Relational Analysis optimization based Taguchi design}

Based on the above discussion, the use of the grey relational analysis coupled with Taguchi design in order to optimize the turning operations with multiple machining characteristics includes the following steps as shown in Fig. 1.

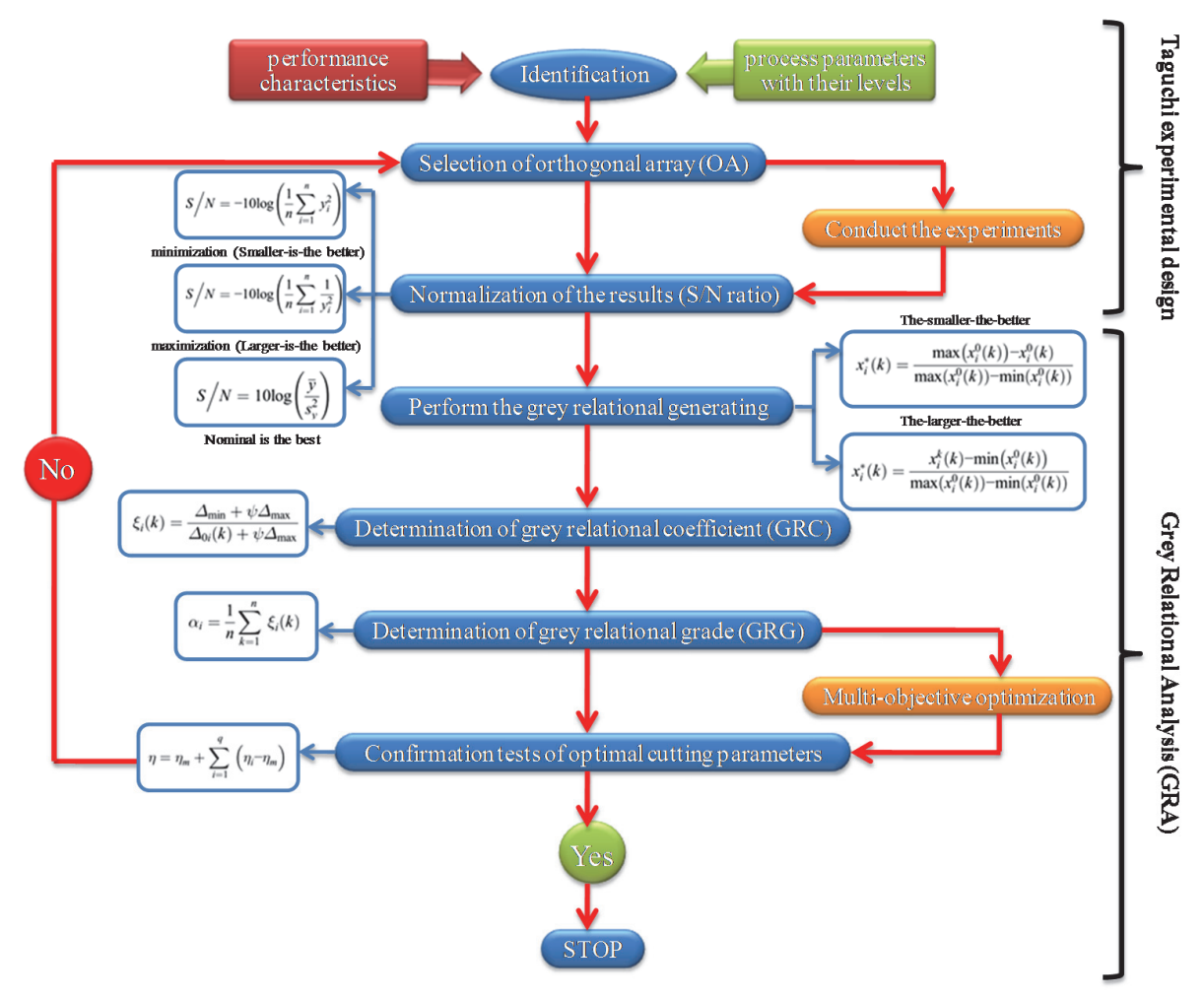

Fig. 1. Loop of multi-objective optimization of grey relational analysis (GRA) based on Taguchi experimental design. 


\section{Experimental set-up}

During this experimental investigation, turning operations were carried out on a conventional lathe of the check company "TOS TRENCIN" SN40 model, with $6.6 \mathrm{~kW}$ spindle power for the turning couple (AISI D3 steel/mixed ceramic inserts CC650) under dry conditions.

\subsection{Work piece material, cutting inserts and tool holders}

The work piece material used was a round bar of AISI D3 steel having $70 \mathrm{~mm}$ in diameter and $400 \mathrm{~mm}$ in length. This lather is a high alloy steel that have several designation such as: DIN 1.2080, JIS SKD1, GB Cr12, AFNOR Z200Cr12. It is a tool steel with high chromium minimum risk of deformation and alteration of dimensions to thermal treatments and it has excellent wear resistance. Its chemical composition is given as follow: $2 \%$ of carbon (C), $0.30 \%$ of Manganese (Mn), $0.25 \%$ of silicon ( $\mathrm{Si}$ ), $12 \%$ of Chrome (Cr), $0.70 \%$ of Tungsten (W).

All turning operations were carried out by three mixed ceramic cutting tools CC650 were manufacturing by Sandvik Coromant and its chemical composition is as follow $\left(\mathrm{Al}_{2} \mathrm{O}_{3}(70 \%)+\mathrm{TiC}(30 \%)\right)$. Each cutting tool is characterized by a nose radius $r=0.8 \mathrm{~mm}, 0.12 \mathrm{~mm}, 0.16 \mathrm{~mm}$ and ISO geometric designation SNGA120408T01020, SNGA120412T01020, SNGA120416T01020 respectively.

Two tool holders are used in this investigation designated by ISO as PSDNN 2525 M12 and PSBNR $2525 \mathrm{M} 12$, respectively. Their geometry of the active part; as shown in Fig. 2 is the same for the following angles: clearance angle $(\alpha)=6^{\circ}$, rake angle $(\gamma)=-6^{\circ}$, and cutting edge inclination angle $(\lambda)=-6^{\circ}$, but it is different to the major cutting edge angle $(\chi r)=45^{\circ}$ and $75^{\circ}$, respectively.

\subsection{Design Experiments and cutting conditions}

Mixed factorial plan reduces of Taguchi $\mathrm{L}_{18}$ was selected as an experimental design to study the impact of different machining parameters $(V c, f, a p)$ which varies at three levels $\left(3^{4}\right)$ and tool geometry $(\chi r, r)$ which varies at two levels $\left(2^{1}\right)$ on the performance characteristics ( $R a$ and $\left.M R R\right)$. The levels of the parameters were selected in the range of intervals advisable by manufacturer of Sandvik Coromant. The cutting parameters chosen to study with their levels are shown in Table 1.

\section{Table 1}

Process parameters and their levels.

\begin{tabular}{lccccc}
\hline Factor & symbol & Unit & Level 1 & Level 2 & Level 3 \\
\hline Cutting speed & $V c$ & $\mathrm{~m} / \mathrm{min}$ & 220 & 307 & 440 \\
Feed rate & $f$ & $\mathrm{~mm} / \mathrm{tr}$ & 0.08 & 0.12 & 0.16 \\
Depth of cut & $a p$ & $\mathrm{~mm}$ & 0.15 & 0.3 & 0.45 \\
Nose radius & $r$ & $\mathrm{~mm}$ & 0.8 & 1.2 & 1.6 \\
major cutting edge angle & $\chi r$ & Degree $\left(^{\circ}\right)$ & 45 & 75 & - \\
\hline
\end{tabular}

\subsection{Measuring equipment}

\subsubsection{Surface roughness measure}

The criterion measures of the surface roughness $(R a)$ are obtained instantly after each pass roughing by means of a Mitutoyo Surftest SJ-201 roughness meter. To prevent errors and recovery for more precision, roughness measurement was performed directly on the work-piece without dismounting it from the lathe. The measurements were repeated three times along three work-piece feed rate directions also placed at $120^{\circ}$ (Fig. 2). The result is considered as the average of these values for each cutting condition. To 
properly characterize the surface roughness of the work-piece, three-dimensional topographic maps were made using an optical platform of metrology modular Altisurf 500.

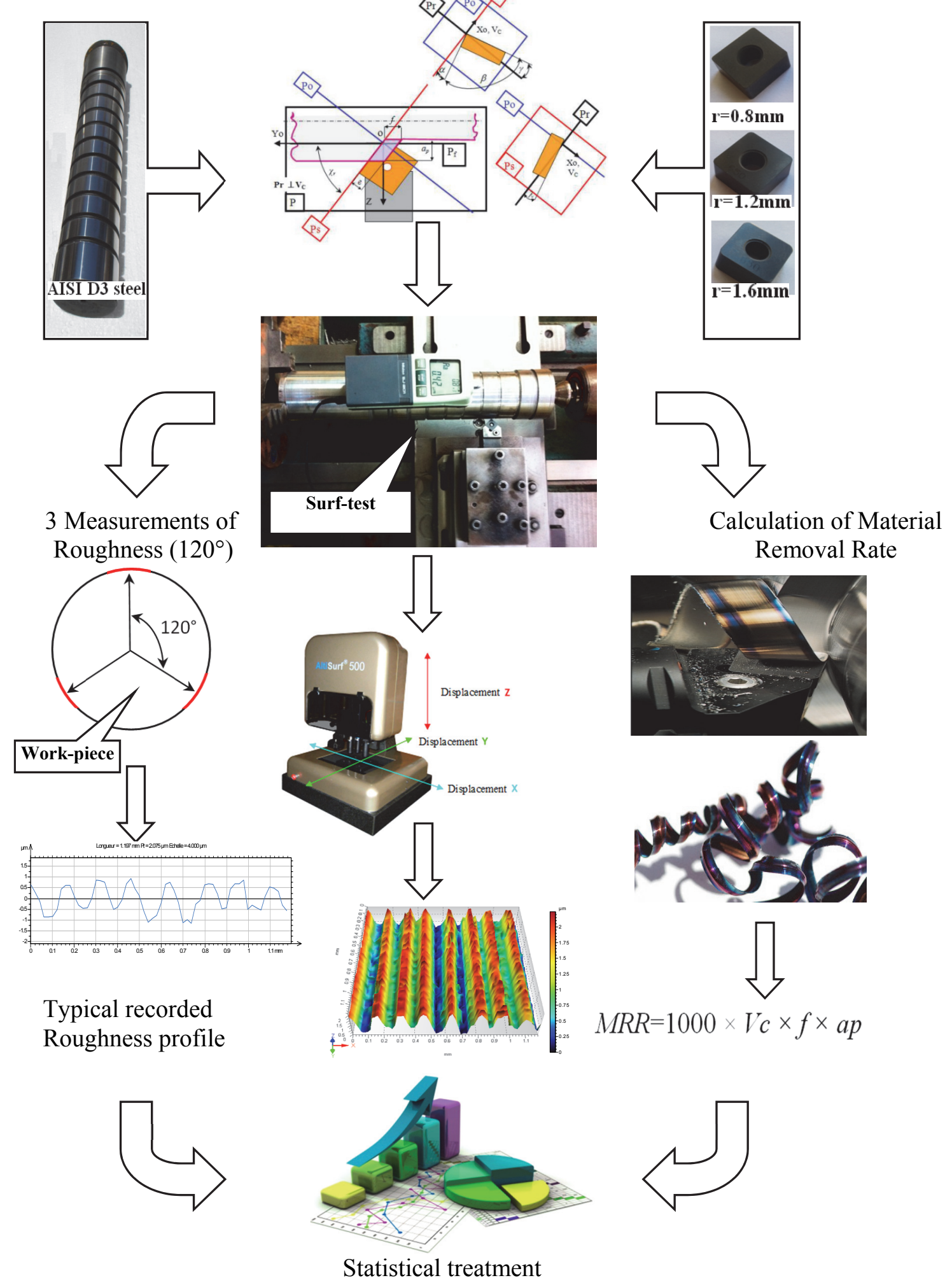

Fig. 2. Schematic diagram of the experimental set-up. 


\subsubsection{Formula of material removal rate}

Material removal rate can be defined as the volume of material removed divided by the machining time. Another way, $M R R$ is to imagine an "instantaneous" material removal rate as the rate at which the crosssection area of material being removed moves through the work-piece. This aspect of machinability is calculated using the following equation:

$$
M R R=1000 \times V c \times f \times a p,
$$

where $V c$ is the cutting speed $(\mathrm{m} / \mathrm{min}), f$ is the feed rate $(\mathrm{mm} / \mathrm{rev})$, and $a p$ is the depth of cut $(\mathrm{mm})$ and $M R R$ is the material removal rate $\left(\mathrm{mm}^{3} / \mathrm{min}\right)$.

\section{Data analysis and results}

The measured values of surface roughness $(R a)$ and the calculated values of material removal rate $(M R R)$ using Eq. (12) with their computed $\mathrm{S} / \mathrm{N}$ ratio in this experimental study which was carried out based on various combinations of machining parameters levels proposed by Taguchi design $\left(\mathrm{L}_{18} \mathrm{OA}\right)$ are shown in Table 2. "The larger is the better" and "The smaller is the better" characteristics are used to calculate the $\mathrm{S} / \mathrm{N}$ ratio in order to maximizing $(M R R)$ and minimizing $(R a)$; i.e. Maximizing surface quality; using equations 2 and 3 , respectively.

\section{Table 2}

Experimental results for surface roughness and material removal rate with their computed $\mathrm{S} / \mathrm{N}$ ratios

\begin{tabular}{|c|c|c|c|c|c|c|c|c|c|}
\hline \multirow{2}{*}{$\begin{array}{c}\text { Trail } \\
\text { no. }\end{array}$} & \multicolumn{5}{|c|}{ Machining parameters } & \multicolumn{4}{|c|}{ Response parameters } \\
\hline & $\begin{array}{l}\chi r \\
\left({ }^{\circ}\right)\end{array}$ & $r(\mathrm{~mm})$ & $V c(\mathrm{~m} / \mathrm{min})$ & $\begin{array}{c}f \\
(\mathrm{~mm} / \mathrm{rev})\end{array}$ & $a p(\mathrm{~mm})$ & $R a(\mu \mathrm{m})$ & $\mathrm{S} / \mathrm{N}(\mathrm{dB})$ & $\begin{array}{c}M R R \\
\left(\mathrm{~mm}^{3} / \mathrm{min}\right)\end{array}$ & $\begin{array}{l}\mathrm{S} / \mathrm{N} \\
(\mathrm{dB})\end{array}$ \\
\hline 1 & 45 & 0.8 & 220 & 0.08 & 0.15 & 0.47 & 6.56 & 2640 & 68.43 \\
\hline 2 & 45 & 0.8 & 307 & 0.12 & 0.3 & 0.59 & 4.63 & 11052 & 80.87 \\
\hline 3 & 45 & 0.8 & 440 & 0.16 & 0.45 & 0.63 & 3.97 & 31680 & 90.02 \\
\hline 4 & 45 & 1.2 & 220 & 0.08 & 0.3 & 0.43 & 7.26 & 5280 & 74.45 \\
\hline 5 & 45 & 1.2 & 307 & 0.12 & 0.45 & 0.55 & 5.14 & 16578 & 84.39 \\
\hline 6 & 45 & 1.2 & 440 & 0.16 & 0.15 & 0.78 & 2.20 & 10560 & 80.47 \\
\hline 7 & 45 & 1.6 & 220 & 0.12 & 0.15 & 0.39 & 8.10 & 3960 & 71.95 \\
\hline 8 & 45 & 1.6 & 307 & 0.16 & 0.3 & 0.57 & 4.83 & 14736 & 83.37 \\
\hline 9 & 45 & 1.6 & 440 & 0.08 & 0.45 & 0.40 & 8.03 & 15840 & 84.00 \\
\hline 10 & 75 & 0.8 & 220 & 0.16 & 0.45 & 1.01 & -0.09 & 15840 & 84.00 \\
\hline 11 & 75 & 0.8 & 307 & 0.08 & 0.15 & 0.43 & 7.40 & 3684 & 71.33 \\
\hline 12 & 75 & 0.8 & 440 & 0.12 & 0.3 & 0.65 & 3.70 & 15840 & 84.00 \\
\hline 13 & 75 & 1.2 & 220 & 0.12 & 0.45 & 0.39 & 8.18 & 11880 & 81.50 \\
\hline 14 & 75 & 1.2 & 307 & 0.16 & 0.15 & 0.54 & 5.35 & 7368 & 77.35 \\
\hline 15 & 75 & 1.2 & 440 & 0.08 & 0.3 & 0.33 & 9.72 & 10560 & 80.47 \\
\hline 16 & 75 & 1.6 & 220 & 0.16 & 0.3 & 0.51 & 5.79 & 10560 & 80.47 \\
\hline 17 & 75 & 1.6 & 307 & 0.08 & 0.45 & 0.41 & 7.74 & 11052 & 80.87 \\
\hline 18 & 75 & 1.6 & 440 & 0.12 & 0.15 & 0.43 & 7.33 & 7920 & 77.97 \\
\hline
\end{tabular}

\subsection{Analysis of variance (ANOVA)}

ANOVA allows determining the significance of input parameters $(\chi r, r, V c, f, a p)$ and their interactions in order of influence on the responses $(R a, M R R)$. The model is based on the calculation of the sums of the squares of the $(\mathrm{S} / \mathrm{N})$ ratios of outputs. First we calculate the sum of squared deviations of the total $(\mathrm{S} / \mathrm{N})$ ratios of outputs. The sum of squared deviations $\mathrm{SS}_{\mathrm{T}}$ represents the difference between each $(\mathrm{S} / \mathrm{N})$ ratio of a measured response $\eta_{i}$ and the total mean $S / N$ ratio $\eta_{m}$, which is given as follows Lindman (1992):

$$
S S_{T}=\sum_{i=1}^{n}\left(\eta_{i}-\eta_{m}\right)^{2}
$$


where $n$ represents the number of trials and $\eta_{i}$ represents the mean $\mathrm{S} / \mathrm{N}$ ratio for the ith trial. The total sum of squared deviations $\mathrm{SS}_{\mathrm{T}}$ is the sum of two terms: variance explained by the regression model $\left(\mathrm{SS}_{\mathrm{d}}\right)$ and random residual variance $\left(\mathrm{SS}_{\mathrm{e}}\right)$ (not explained by the model) which is written as follows:

$$
S S_{T}=S S_{d}+S S_{e}
$$

Another statistical tool that allows determining the significant effect of each input parameter on each output response, named (F test) by Ross (1996).

The results of variance analysis (ANOVA) for $\mathrm{S} / \mathrm{N}(R a)$ are shown in Table 3 and the contribution of significant terms on $R a$ are presented in Fig. 3 (a). It is seen that the feed rate occupies the first position of influencing on the quality of surface with a contribution of $50.21 \%$, because during the feed rate of cutting tool of work-piece in turning process, the tool shape generates helicoids furrows on surface of work-piece. These furrows are deeper and broader as the feed rate increases, therefore the surface quality decreases. The second influential machining parameter is the nose radius of the tool with an impact of $20.27 \%$. A popular established model presented by Yallese et al. (2004) to predict the surface roughness, with a cutting tool that have nose radius different of zero, is:

$$
R a=\frac{f^{2}}{32 \times r},
$$

where $R a$ is the arithmetic mean roughness $(\mu \mathrm{m}), f$ is the feed rate $(\mathrm{mm} / \mathrm{rev}), r$ is the cutting tool nose radius (mm). Based on the Eq. (15) the uses of the largest tool nose radius with little feed rate improves the quality of surface. Similarly, Singh and Rao (2007); Makadia and Nanavati (2013) found that the feed rate is the most significant factor followed by tool nose radius affecting the surface roughness. The interaction $f \times a p$ comes in third position with an effect of $12.69 \%$ on quality of surface, the same interaction significance found by Aslan et al. (2007) when turning hardened AISI 4140 steel with $\mathrm{Al}_{2} \mathrm{O}_{3}$ + TiCN mixed ceramic tool. The factors $(\chi r, V c, a p)$ and the other interactions are having a slightly effect on quality of surface.

\begin{tabular}{|c|c|c|c|c|c|c|}
\hline Source & SS & DF & MS & F-value & Cont. $\%$ & Remarks \\
\hline$\chi r$ & 1.0755 & 1 & 1.0755 & 116.9 & 1.07 & Significant \\
\hline$r$ & 20.4583 & 1 & 20.4583 & 2223.73 & 20.27 & Significant \\
\hline$V c$ & 0.0569 & 1 & 0.0569 & 6.18 & 0.06 & Insignificant \\
\hline$f$ & 50.6817 & 1 & 50.6817 & 5508.88 & 50.21 & Significant \\
\hline$a p$ & 1.3091 & 1 & 1.3091 & 142.29 & 1.3 & Significant \\
\hline$\chi r \times r$ & 1.3651 & 1 & 1.3651 & 148.38 & 1.34 & Significant \\
\hline$\chi r \times V c$ & 0.0179 & 1 & 0.0179 & 1.95 & 0.02 & Insignificant \\
\hline$\chi r \times f$ & 1.1715 & 1 & 1.1715 & 127.34 & 1.16 & Significant \\
\hline$\chi r \times a p$ & 3.8569 & 1 & 3.8569 & 419.23 & 3.82 & Significant \\
\hline$r \times V c$ & 2.7503 & 1 & 2.7503 & 298.95 & 2.72 & Significant \\
\hline$r \times f$ & 0.1536 & 1 & 0.1536 & 16.7 & 0.15 & Insignificant \\
\hline$r \times a p$ & 2.9522 & 1 & 2.9522 & 320.89 & 2.92 & Significant \\
\hline$V c \times f$ & 0.3393 & 1 & 0.3393 & 36.88 & 0.34 & Significant \\
\hline$V c \times a p$ & 1.9258 & 1 & 1.9258 & 209.33 & 1.91 & Significant \\
\hline$f \times a p$ & 12.8056 & 1 & 12.8056 & 1391.91 & 12.69 & Significant \\
\hline Error & 0.0183 & 2 & 0.0092 & & 0.02 & \\
\hline Total & 100.938 & 17 & & & 100 & \\
\hline
\end{tabular}

Table 3

From the analysis of Table 4 and Fig. 3 (b), it can be apparent that $V c, f$, and ap have a significant effect on $(M R R)$. Nevertheless, ap is the most significant factor associated with $M R R$ with $54.85 \%$. The next largest factors influencing $M R R$ is $f$ followed by $V c$. Their contributions are $21.84 \%$ and $21.64 \%$, respectively. The rest of terms do not represent any significant effects on $M R R$. The same order of significant effect of machining parameters on the $M R R$ was found by Bouzid et al. (2014) when turning of X20Cr13 stainless steel. 
Table 4

Analysis of Variance for $\mathrm{S} / \mathrm{N}(M R R)$

\begin{tabular}{ccccccc}
\hline Source & SS & DF & MS & F-value & Cont. \% & Remarks \\
\hline$V c$ & 107.757 & 1 & 7.253 & 10 & 21.64 & Significant \\
$f$ & 108.743 & 1 & 8.151 & 11.24 & 21.84 & Significant \\
$a p$ & 273.174 & 1 & 11.392 & 15.71 & 54.85 & Significant \\
$V c \times f$ & 0.306 & 1 & 0.264 & 0.36 & 0.06 & Insignificant \\
$V c \times a p$ & 0.034 & 1 & 0.027 & 0.04 & 0.01 & Insignificant \\
$f \times a p$ & 0.012 & 1 & 0.012 & 0.02 & 1.60 & Insignificant \\
Error & 7.978 & 11 & 0.725 & & 100 & \\
\hline Total & 498.004 & 17 & & & & \\
\hline
\end{tabular}
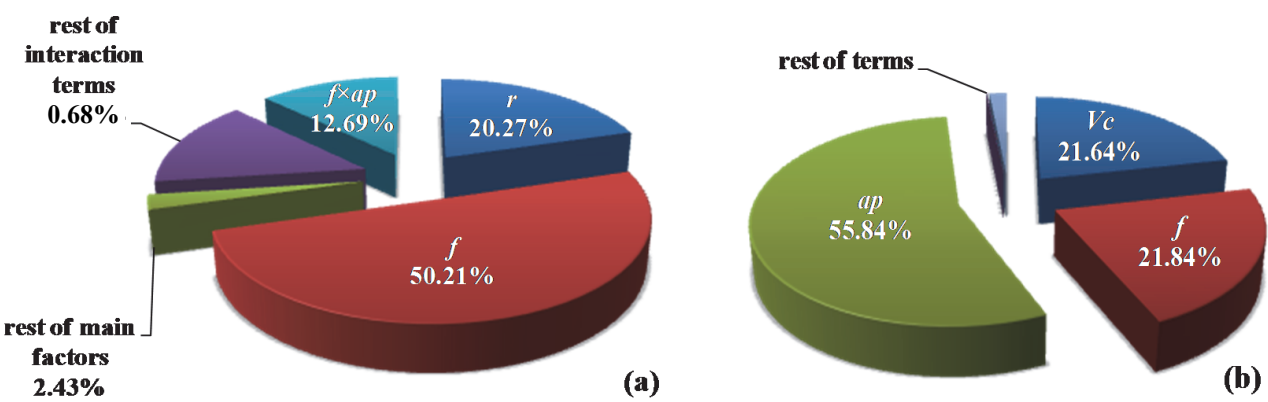

Fig. 3. Contribution of significant terms on: (a) Surface roughness $(R a)$, (b) Material removal rate $(M R R)$

\subsection{Pareto analysis}

Pareto analysis is a creative statistical technique which aims to identify the important causes for resolving the most problems. It is based on the Pareto principle also known as 80/20 rule which in general means that $80 \%$ of problems may be caused by as few as $20 \%$ of causes (Karuppusami \& Gandhinathan, 2006). This technique was considered in this study to check and confirm the results obtained by ANOVA analysis (Fig. 4). This chart presents the ranking of the influencing machining parameters and their interactions in descending order on the $R a$ and $M R R$. The effects of factors and their interactions on the responses are standardized for a better comparison. The standardized values called (F-value) in this chart are obtained by dividing the mean squares of each factor by the error of mean squares. The more standardized the effect, the higher the factor considered influence. If the F-values which correspond to the machining parameters and their Interactions are greater than 18.51 and 4.84 for $(R a)$ and $(M R R)$, respectively; the effects are significant. By against, if the values of F-values are less than 18.51 and 4.84 for $(R a)$ and $(M R R)$, respectively; the effects are not significant. The confidence interval chosen is $95 \%$ $(\alpha=0.05)$.

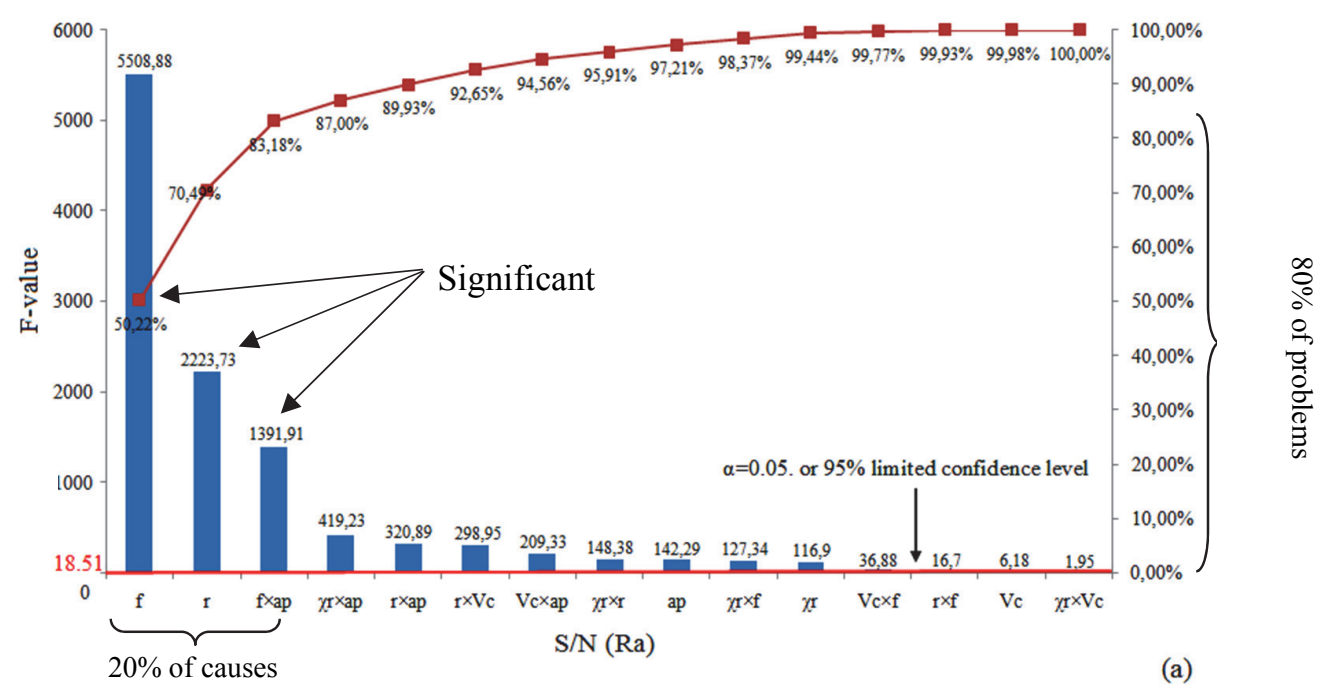




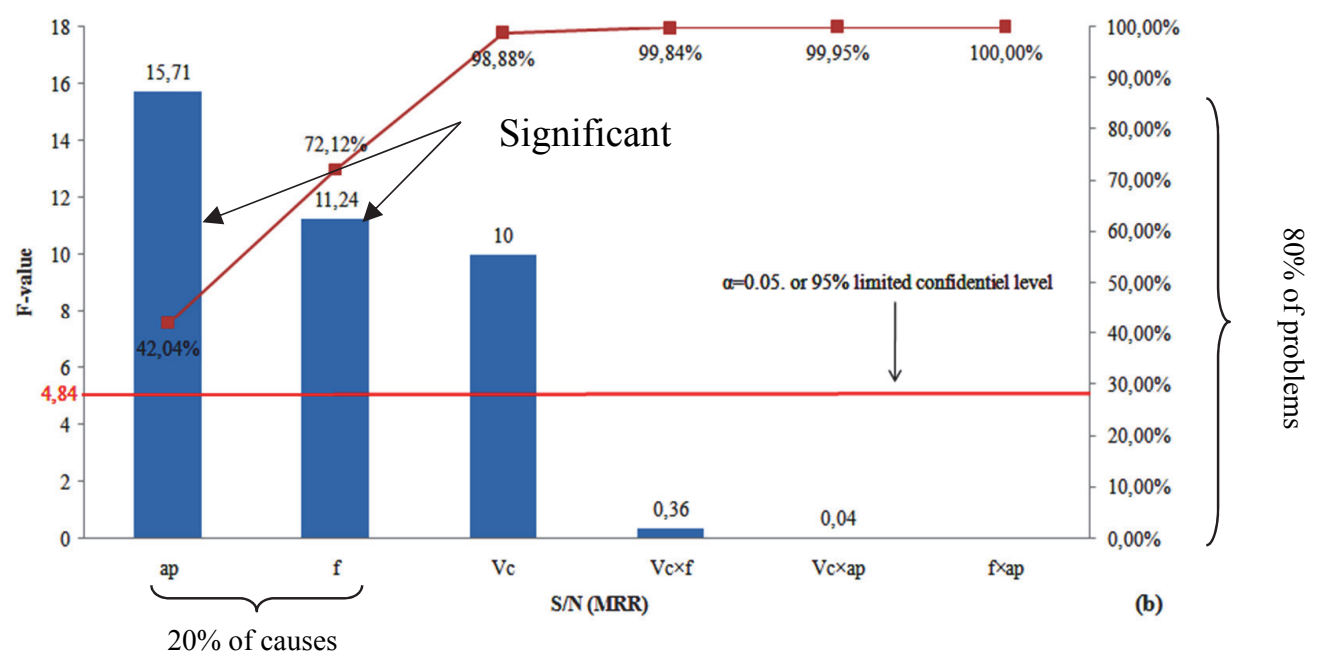

Fig. 4. Pareto analysis chart, for effect of machining parameters on: (a) surface roughness and (b) material removal rate.

\subsection{Main effect factors and their interactions on responses (3D plots and contours)}

The main effect plots for $\mathrm{S} / \mathrm{N}$ ratios of $(R a)$ and $(M R R)$ are presented in Fig. $5(\mathrm{a}, \mathrm{b})$, respectively. Response graphs show the evolution of $\mathrm{S} / \mathrm{N}$ ratio of responses in function of variation of levels for each machining parameters. The values of the plotted points in Fig. $5(a, b)$ of the $\mathrm{S} / \mathrm{N}$ ratio for surface roughness and material removal rate which correspond to each level of machinability parameters are given in Table $5(\mathrm{a}, \mathrm{b})$ respectively. The influence of cutting parameters on the responses can be easily determined through delta value that represents the difference between max and $\min$ of $\mathrm{S} / \mathrm{N}$ ratios of responses as shown in Table $5(a, b)$. The higher the value of the delta, the more influential is the cutting parameter. It can be seen in Table $5(\mathrm{a}, \mathrm{b})$ that the significance of all main factors is ranking in descending order of influence on the responses.

It is notable from Fig. 5 (a) and Table 5 (a) that the most machining parameter affecting surface quality is the feed rate $(f)$ followed by tool nose radius $(r)$. The others factors represent less effects on surface quality. Also, it is clear that the surface quality deteriorates by increasing feed rate. By contrast, the increasing of cutting insert nose radius improves the surface quality $(R a)$.

From Fig. 5 (b) and Table 5 (b), it can be observed clearly that all main factors $(V c, f$, ap) have a significant effect on material removal rate. The descending order of influence of all main factors on responses is as follow: depth of cut, feed rate followed by cutting speed. By increasing all main factors $(V c, f, a p)$ we can improve the productivity $(M R R)$. It can be observed that the same ranking in descending order of influence of all main factors on responses are obtained by ANOVA analysis and is also confirmed by Pareto chart.

\section{Table 5}

$\mathrm{S} / \mathrm{N}$ response table for: (a) surface roughness (Smaller is better), (b) material removal rate (Larger is better)

Table 5a

\begin{tabular}{cccccc}
\hline Level & $\chi r$ & $r$ & $V c$ & $f$ & $a p$ \\
\hline 1 & 5.636 & 4.361 & 5.968 & 7.786 & 6.157 \\
2 & 6.125 & 6.308 & 5.85 & 6.181 & 5.989 \\
3 & - & 6.973 & 5.823 & 3.675 & 5.496 \\
Delta & 0.489 & 2.611 & 0.145 & 4.11 & 0.661 \\
Rank & 4 & 2 & 5 & 1 & 3 \\
\hline
\end{tabular}

Table 5b

\begin{tabular}{cccc}
\hline Level & $V c$ & $f$ & $a p$ \\
\hline 1 & 76.8 & 76.59 & 74.58 \\
2 & 79.69 & 80.11 & 80.61 \\
3 & 82.82 & 82.61 & 84.13 \\
Delta & 6.02 & 6.02 & 9.54 \\
Rank & 3 & 2 & 1 \\
\hline
\end{tabular}




\section{Main Effects Plot for S/N ratios (Ra)}

Data Means

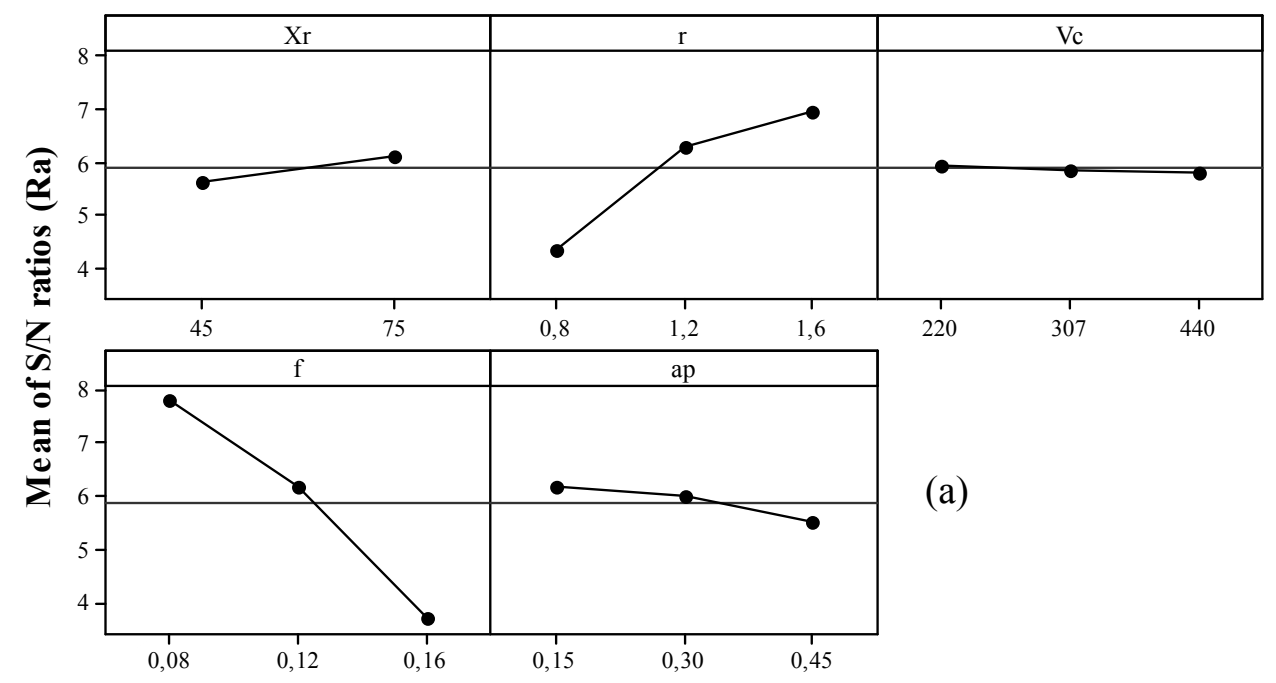

Signal-to-noise: Smaller is better

Main Effects Plot for S/N ratios (MRR)

Data Means

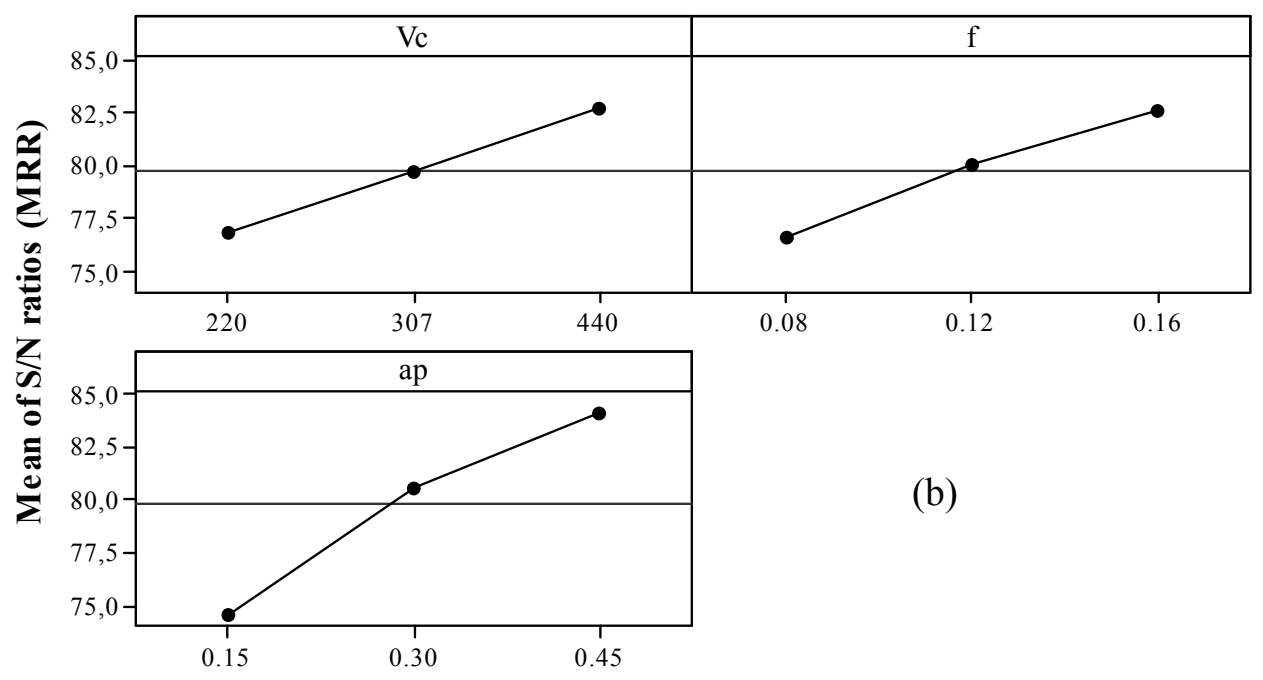

Signal-to-noise: Larger is better

Fig. 5. Main effect's plots of $\mathrm{S} / \mathrm{N}$ for: (a) surface roughness, (b) material removal rate

In order to check the influence of interaction of the depth of cut and the feed rate on the surface quality $(\mathrm{S} / \mathrm{N}$ ratio for $\mathrm{Ra}$ ), 3D response surface for the effect of the interaction is drawn in Fig. 6 (a). Variables not represented in the figure are held constant at the middle level $\left(\chi r=60^{\circ}, r=1.2 \mathrm{~mm}, V c=330 \mathrm{~m} /\right.$ $\mathrm{min}$ ). This figure indicates that, for a given depth of cut, the surface quality is sensitive to the feed rate because the increase of this latter deteriorates quickly the surface quality. This is consistent with the conclusion of research work published by Bouzid et al. (2015) where they remarked that the surface roughness $(R a)$ rapidly increases by increasing feed rate. However, this decrease in surface quality becomes increasingly small with lower values of the depth of cut. 
Fig. 6 (b) shows the response surface for $\mathrm{S} / \mathrm{N}(R a)$ in the form of a contour. It is remarkable after this figure that for any given values of depth of cut and which belongs to the interval of this study, the best surface quality is found for small values of feed rate in the study interval. Also, at higher depths of cut, better quality of surface is obtainable from $0.3 \mathrm{~mm}$ to $0.45 \mathrm{~mm}$.
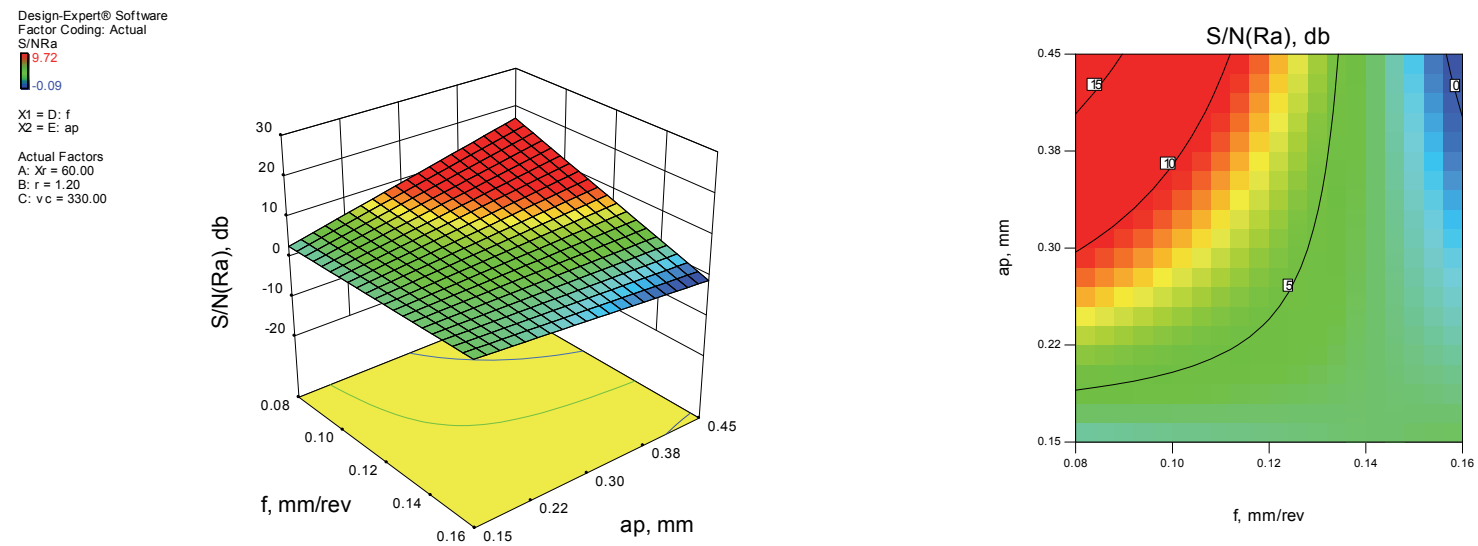

Fig. 6. $3 \mathrm{D}$ plot and contour for the response surface for: Effect of $(f \times a p)$ on the $\mathrm{S} / \mathrm{N}(R a)$

\section{4 $2 D$ profile and $3 D$ topography of turned surface}

Fig. 7 shows a representative example of 2D profile and 3D image of turned surface envisioned by means of optical platform of metrology modular Altisurf 500 with isometric view. The aim of this investigation is to examine the effect of both feed rate and nose radius on surface roughness through a comparison between 2D profile and 3D topography of turned surfaces obtained as a result of various levels combinations of machining parameters. Turning operations were conducted by the same levels of machining parameters except the feed rate and tool nose radius; for the turned surface (a): $\chi r=75^{\circ}, r=$ $0.8 \mathrm{~mm}, V c=220 \mathrm{~m} / \mathrm{min}, f=0.08 \mathrm{~mm} / \mathrm{rev}, a p=0.15 \mathrm{~mm}$, for the turned surface (b): $\chi r=75^{\circ}, r=0.8$ $\mathrm{mm}, V c=220 \mathrm{~m} / \mathrm{min}, f=0.16 \mathrm{~mm} / \mathrm{rev}, a p=0.15 \mathrm{~mm}$; for the turned surface (c): $\chi r=75^{\circ}, r=1.6 \mathrm{~mm}$, $V c=220 \mathrm{~m} / \mathrm{min}, f=0.16 \mathrm{~mm} / \mathrm{rev}, a p=0.15 \mathrm{~mm}$. It clearly appears by a comparison in Fig. $7(\mathrm{a}, \mathrm{b})$ that the use of large feed rate yields a bad surface roughness. Because the distance between roughness asperities increases with the increase of feed rate. Whereas, by a comparison of turned surfaces (b and c) in Fig. 7 it is notable that that the use of large nose radius improves the surface roughness by the crushing of the asperities. When the nose radius of cutting tool increases, the contact languor between the beak of the tool and the machined surface is increased and this leads to crushing of the asperities and traces of advance of the tool as shown in Fig. 7 (c).

\section{Regression equations}

Regression analysis is a computational technique that enables to found the functional relationship between the machining parameters (control factors) and the performance characteristics. The predictive equations for the performance characteristics were formulated by linear regression model with interactions given by Eq. (16).

$$
Y=b_{0}+\sum_{i=1}^{k} b_{i} X_{i}+\sum_{i j}^{k} b_{i j} X_{i} X_{j}+\varepsilon_{i}
$$

where $b_{0}$ is the free term of the regression equation, the coefficients $b_{1}, b_{2} \ldots b_{k}$ and $b_{12}, b_{13}, b_{k-1}$ are the linear and interacting terms, respectively. $\mathrm{X}_{\mathrm{i}}$ represents the input parameters; $(\chi r, r, V c, f, a p)$ for $(R a)$ and $(V c, f, a p)$ for $(M R R)$; and $Y$ represents the outputs (surface roughness, material removal rate). Correlative mathematical models of $R a$ and $M R R$ are given below by Eq. (17) and Eq. (18), respectively, 
with respective coefficients of determination $\mathrm{R}^{2}$ of $99.72 \%$ and $99.77 \%$. These mathematical equations are useful for the estimation of outputs parameters in the range of intervals selected in this study.

$$
\begin{aligned}
R a= & -0.751523-0.0390656 \chi r+2.11283 r+0.00839753 V c+20.5609 f-9.98742 a p \\
& -0.00225299 \chi r \times r+5.98103 \mathrm{e}-005 \chi r \times V c+0.116648 \chi r \times f+0.00051299 \chi r \times a p- \\
& 0.00318008 r \times V c-23.6922 r \times f+6.56501 r \times a p-0.0255462 V c \times f-0.0163664 V c \times a p \\
& +53.2321 f \times a p \\
M R R= & 12835.2-40.4339 V c-105222 f-41353.3 a p+324.193 V c \times f+126.452 V c \times a p+ \\
& 332351 f \times a p
\end{aligned}
$$
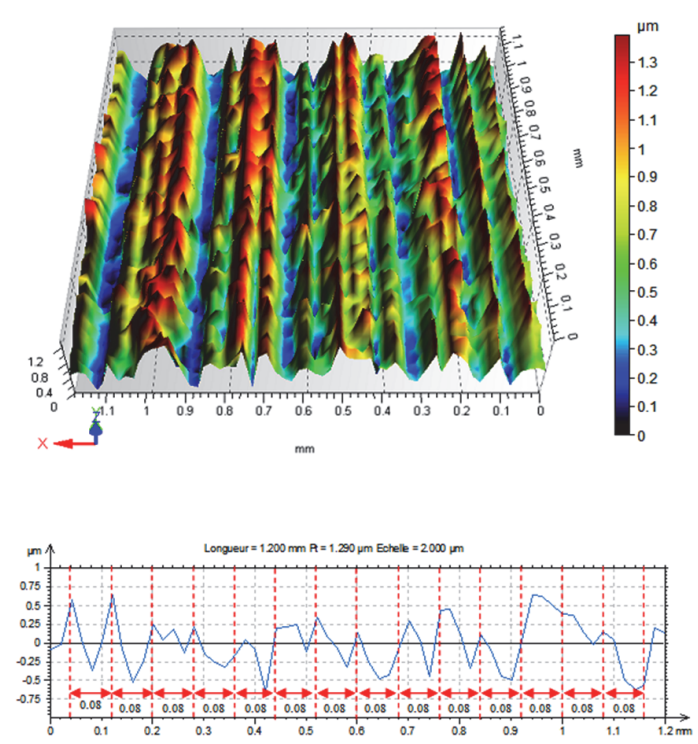

$\chi r=75^{\circ}, r=0.8 \mathrm{~mm}, V c=220 \mathrm{~m} / \mathrm{min}, f=0.08 \mathrm{~mm} / \mathrm{rev}, a p=0.15 \mathrm{~mm}$

(a)
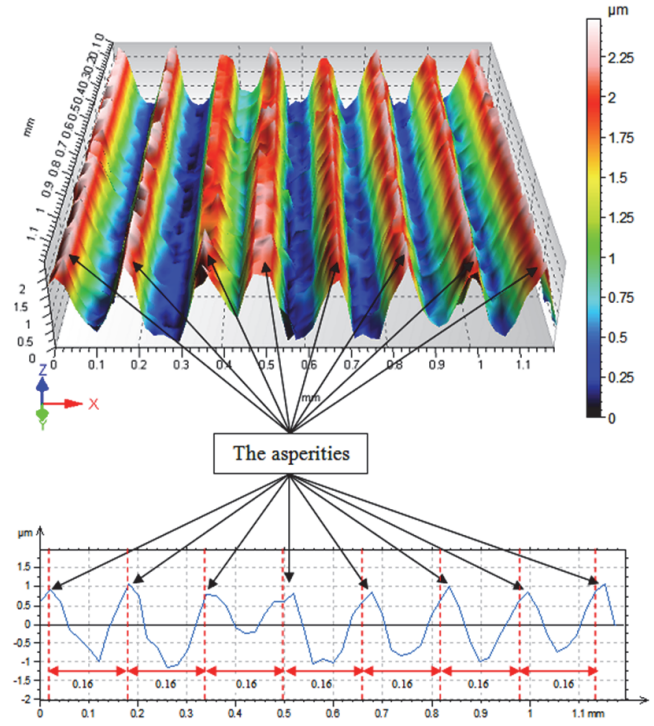

$\chi r=75^{\circ}, r=0.8 \mathrm{~mm}, V c=220 \mathrm{~m} / \mathrm{min}, f=0.16 \mathrm{~mm} / \mathrm{rev}, a p=0.15 \mathrm{~mm}$

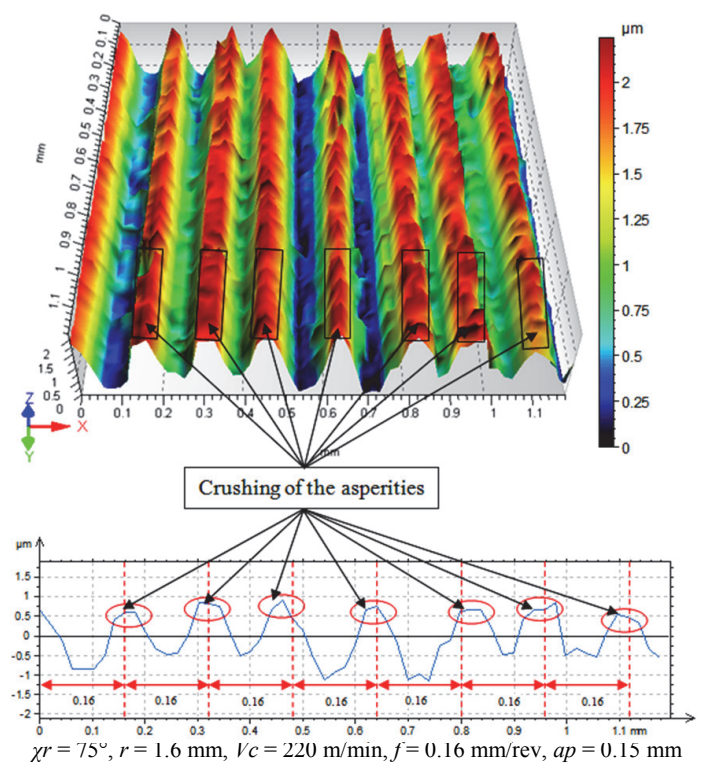

(c)

Fig. 7. Example of 2D profile and 3D topography of turned surface 
To verify the reliability of correlative mathematical models of $R a$ and $M R R$, the normal probability plot vs. residuals were traced in Fig. 8 (a, b) respectively. It can be seen from Fig. 8 (a, b) that the cloud of residuals is reasonably distributed around to the straight line and there are no unusual data points in the data set. This implies that errors are distributed normally.

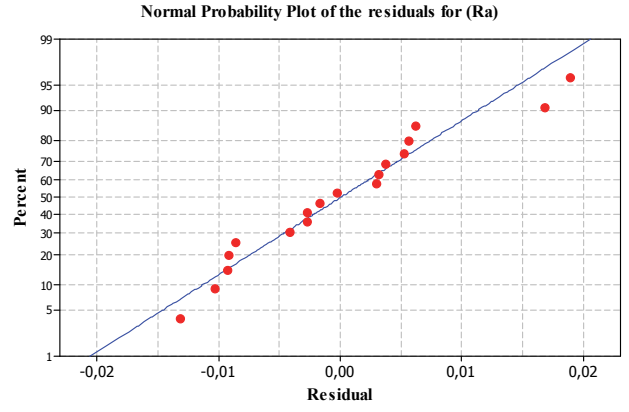

(a)

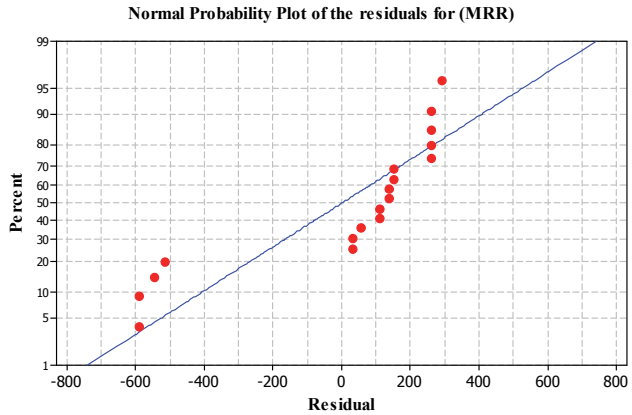

(b)

Fig. 8. Normal probability plot of residuals for: (a) surface roughness, (b) material removal rate

Fig. $9(a, b)$ shows the residuals which are associated with the eighteen experimental runs of surface roughness and material removal rate, respectively. This residual is equal to the difference between the observed and predicted values of the output responses. The residuals of surface roughness belong to the interval of -0.015 to $0.020 \mu \mathrm{m}$ versus the residuals of material removal rate, which belong at the interval of -600 to $400 \mathrm{~mm}^{3} / \mathrm{min}$. The residuals do not represent any obvious pattern, this implies that the predictive equations are reliable for estimating the responses at any particular design points which belong at the range intervals selected in this study.

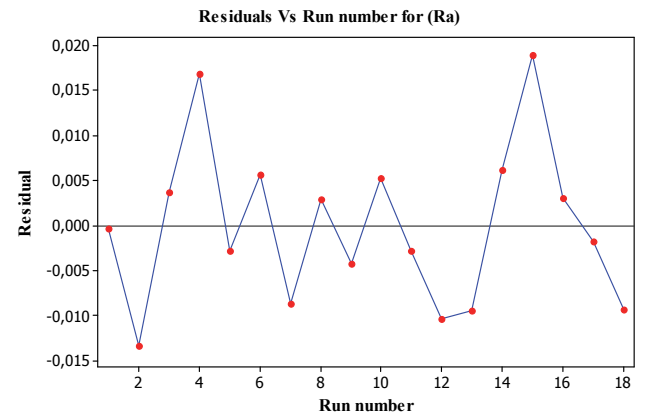

(a)

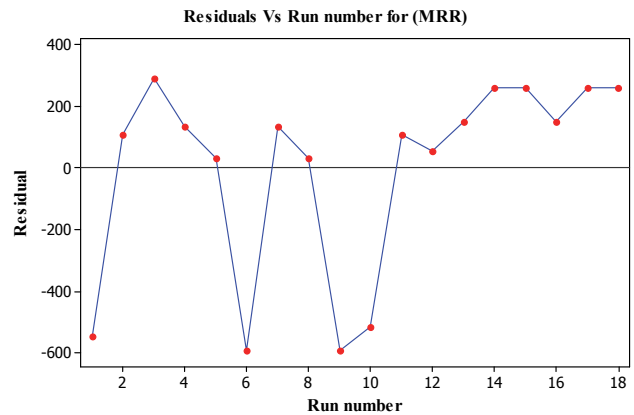

(b)

Fig. 9. Plot of residuals vs. run numbers for: (a) surface roughness, (b) removal material rate

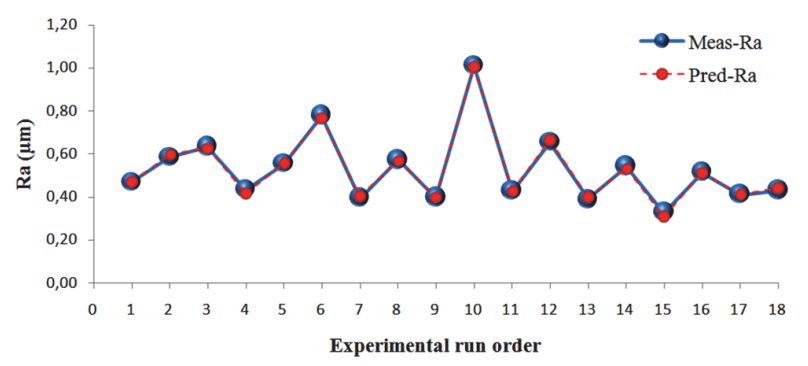

(a)

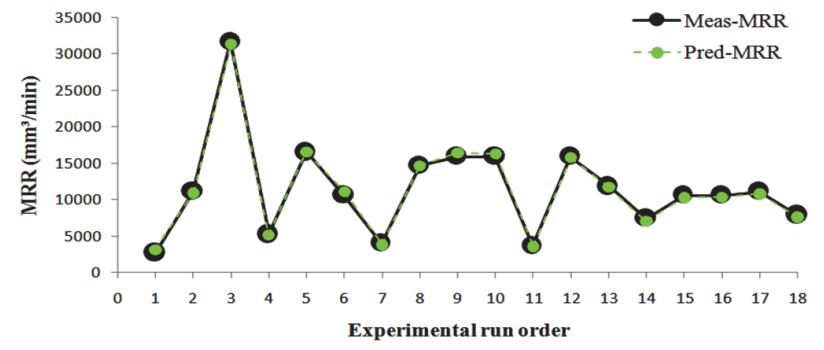

(b)

Fig. 10. Measured vs. predicted values of performance characteristics: (a) surface roughness, (b) material removal rate. 
Fig. $10(\mathrm{a}, \mathrm{b})$ also shows a comparison between the predicted values of $R a$ and $M R R$, respectively obtained from the linear regression equations and the observed ones. This comparison proves that the estimated output responses are very close to those measured (good agreement between predicted and observed values). These figures confirm that the linear regression models are suitable for estimating the responses without carrying out experimental runs with respect to the range intervals considered in this investigation.

\section{Multi-objective optimization using GRA based Taguchi design}

The identification of the optimal levels combination of machining parameters using multi-objective optimization (GRA) was carried out based on the $\mathrm{S} / \mathrm{N}$ ratio of measured and calculates data of surface roughness $(R a)$ and material removal rate $(M R R)$, respectively. They are obtained during the dry turning operations of AISI D3 steel with ceramic cutting insert (CC650) based on Taguchi design ( $\left.\mathrm{L}_{18} \mathrm{OA}\right)$. The simultaneous improvement in term of maximization both surface quality and productivity are proposed as an objective function. The use of this technique optimization includes the following steps which is mentioned in the second part of this paper.

Step 1: The normalization of $\mathrm{S} / \mathrm{N}$ ratios for $R a$ and $M R R$ in the range between zero and one using Eq. 5 (The larger-the-better) were determined for grey relational generation. The normalized data are given in Table 6.

Step 2: Calculation of $\Delta_{0 i}(k)$ for normalized values of $\mathrm{S} / \mathrm{N}$ ratio $(R a, M R R)$ using Eq. (7) is necessary for the computation of grey relational coefficients (GRC). Grey relational coefficients (GRC) were computed using Eq. 6 for the determination of grey relational grade (GRG). $\Delta_{0 i}(k)$ and GRC values are given in Table 6.

Step 3: Grey relational grade (GRG) was computed by Eq. (10). The calculated results of GRG are shown in Table 6. This implies that the multi-objective optimization is converted to a single equivalent objective optimization.

Table 6

Results of grey relational generation, calculation of $\Delta_{0 \mathrm{i}}(\mathrm{k})$, grey relational coefficient and grey relational grade

\begin{tabular}{|c|c|c|c|c|c|c|c|}
\hline \multirow{3}{*}{ Trail no. } & \multicolumn{2}{|c|}{ Grey relational generation } & \multicolumn{2}{|c|}{ Calculation of $\Delta_{0 \mathrm{i}}(\mathrm{k})$} & \multicolumn{2}{|c|}{ Grey relational coefficient } & \multirow{2}{*}{$\frac{\text { Grey relational grade }}{\text { GRG }}$} \\
\hline & $\mathrm{S} / \mathrm{N}$ & $\mathrm{S} / \mathrm{N}(M R R)$ & \multirow[t]{2}{*}{$\mathrm{S} / \mathrm{N}$} & $\mathrm{S} / \mathrm{N}(M R R)$ & \multirow[t]{2}{*}{$\mathrm{S} / \mathrm{N}$} & \multirow[t]{2}{*}{$\mathrm{S} / \mathrm{N}$} & \\
\hline & \multicolumn{2}{|c|}{ Larger-the-better } & & & & & \\
\hline Ideal sequence & 1 & 1 & 1 & 1 & 1 & 1 & \\
\hline 1 & 0,708 & 0,000 & 0,292 & 1,00 & 0,632 & 0,333 & 0,483 \\
\hline 2 & 0,531 & 0,576 & 0,469 & 0,42 & 0,516 & 0,541 & 0,529 \\
\hline 3 & 0,470 & 1,000 & 0,530 & 0,00 & 0,485 & 1,000 & 0,743 \\
\hline 4 & 0,774 & 0,279 & 0,226 & 0,72 & 0,689 & 0,409 & 0,549 \\
\hline 5 & 0,578 & 0,739 & 0,422 & 0,26 & 0,543 & 0,657 & 0,600 \\
\hline 6 & 0,306 & 0,558 & 0,694 & 0,44 & 0,419 & 0,531 & 0,475 \\
\hline 7 & 0,851 & 0,163 & 0,149 & 0,84 & 0,771 & 0,374 & 0,572 \\
\hline 8 & 0,550 & 0,692 & 0,450 & 0,31 & 0,526 & 0,619 & 0,573 \\
\hline 9 & 0,845 & 0,721 & 0,155 & 0,28 & 0,763 & 0,642 & 0,703 \\
\hline 10 & 0,000 & 0,721 & 1,000 & 0,28 & 0,333 & 0,642 & 0,488 \\
\hline 11 & 0,786 & 0,134 & 0,214 & 0,87 & 0,700 & 0,366 & 0,533 \\
\hline 12 & 0,445 & 0,721 & 0,555 & 0,28 & 0,474 & 0,642 & 0,558 \\
\hline 13 & 0,858 & 0,605 & 0,142 & 0,39 & 0,779 & 0,559 & 0,669 \\
\hline 14 & 0,598 & 0,413 & 0,402 & 0,59 & 0,554 & 0,460 & 0,507 \\
\hline 15 & 1,000 & 0,558 & 0,000 & 0,44 & 1,000 & 0,531 & 0,765 \\
\hline 16 & 0,638 & 0,558 & 0,362 & 0,44 & 0,580 & 0,531 & 0,555 \\
\hline 17 & 0,818 & 0,576 & 0,182 & 0,42 & 0,733 & 0,541 & 0,637 \\
\hline 18 & 0,780 & 0,442 & 0,220 & 0,56 & 0,695 & 0,473 & 0,584 \\
\hline
\end{tabular}


Step 4: Main effect plot for (GRG) was traced in order to select the optimal levels combination (Fig. 11). The mean of GRG ratio for each level of the machining parameters is presented in Table 7. In grey relational analysis the highest value of (GRG) corresponds to the best levels combination of machining parameters. Therefore, the optimal level of the machining parameters is the level with the greatest GRG value. So it can be concluded that the best level for each machining parameter was found as follow (Fig. 11): $\chi r_{2} r_{3} V c_{3} f_{1} a p_{3}$, in other words, the optimal levels combination for $R a$ and $M R R$ were obtained at a major cutting edge angle of $75^{\circ}$, insert radius of $1.6 \mathrm{~mm}$, cutting speed of $440 \mathrm{~m} / \mathrm{min}$, feed of $0.08 \mathrm{~mm} / \mathrm{rev}$ and depth of cut of $0.45 \mathrm{~mm}$. The results of the use of this optimal levels combination are: $R a=0.41 \mu \mathrm{m}$ and $M R R=15840 \mathrm{~mm}^{3} / \mathrm{min}$.

\section{Main Efiects Plot for GRG Data Means}

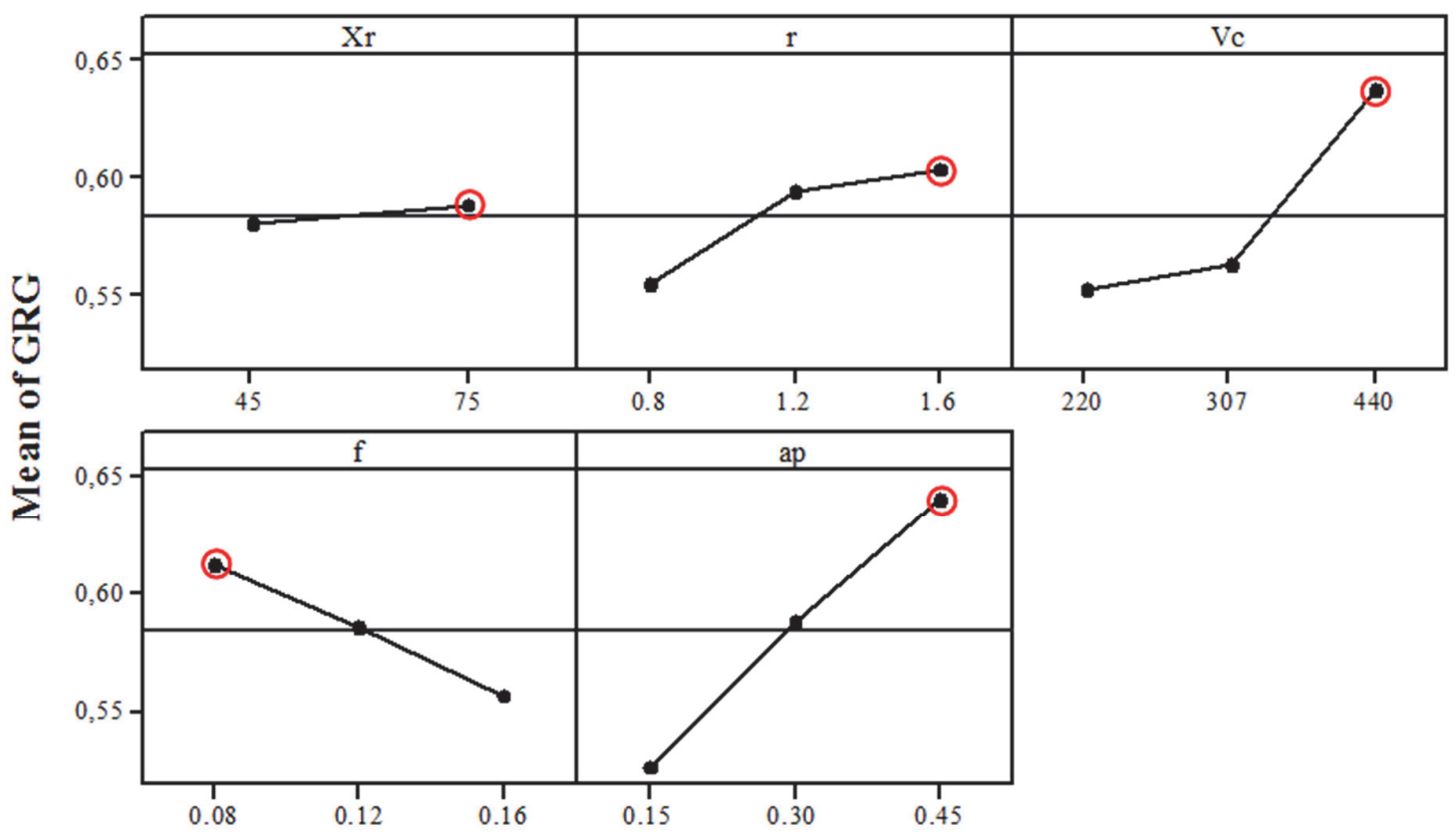

Fig. 11. Main effect's plots for GRG

Table 7

Mean of GRG ratio for each level of the machining parameters

\begin{tabular}{cccccc}
\hline Level & $\chi r$ & $r$ & $V c$ & $f$ & $a p$ \\
\hline 1 & 0.580 & 0.555 & 0.552 & 0.611 & 0.525 \\
2 & 0.589 & 0.594 & 0.563 & 0.585 & 0.588 \\
3 & - & 0.604 & 0.637 & 0.556 & 0.639 \\
Delta & 0.009 & 0.049 & 0.085 & 0.055 & 0.114 \\
Rank & 5 & 4 & 2 & 3 & 1 \\
\hline
\end{tabular}

Step 5: In order to confirm the selected optimal levels combination of machining parameters through the use of GRA technique for the improvement of surface roughness and material removal rate, a comparison assessment was performed between the values of grey relational grade obtained from the optimal experiment with that predicted $\hat{\eta}$ by using the Eq. (11). Based on the results in Table 8 , a notable agreement was remarked between the value found experimentally $(0.69)$ calculated by the estimation formula (0.74). While the grey relational grade was improved from initial levels combination $\left(\chi r_{2} r_{2} V c_{2}\right.$ $\left.f_{2} a p_{2}\right)$ to the optimal levels combination of machining parameters $\left(\chi r_{2} r_{3} V c_{3} f_{1} a p_{3}\right)$ by 0.13 . According 
to confirmation runs, the surface roughness and material removal rate are ameliorating approximately $1.21,0.69$ times, respectively.

Table 8

Results of the confirmation experiment

\begin{tabular}{lccc}
\hline & $\begin{array}{c}\text { Initial machining } \\
\text { parameters }\end{array}$ & \multicolumn{2}{c}{ Optimal machining parameters } \\
\cline { 2 - 4 } & $\chi r_{2} r_{2} V c_{2} f_{2} a p_{2}$ & Prediction & Experiment \\
\hline Level & 0.50 & $\chi r_{2} r_{3} V c_{3} f_{1} a p_{3}$ & $\chi r_{2} r_{3} V c_{3} f_{1} a p_{3}$ \\
$R a(\mu \mathrm{m})$ & 11052 & - & 0.41 \\
$M R R\left(\mathrm{~mm}^{3} / \mathrm{min}\right)$ & 0.56 & - & 15840 \\
GRG & & 0.74 & 0.69 \\
Improvement of GRG & & 0.13 & \\
\hline
\end{tabular}

\section{Conclusions}

This investigation has detailed the procedure of applying the grey relational analysis based on Taguchi design for a simultaneous optimization in turning process. Through the results obtained in this study, the following conclusions can be drawn:

1. The mixed orthogonal array of Taguchi $\mathrm{L}_{18}$ is adopted in this investigation to get a small number of experiment runs for identifying the optimal levels of machining parameters using grey relational analysis.

2. Based on the ANOVA analyse of $\mathrm{S} / \mathrm{N}$ ratio for $(R a)$, it's found that the feed rate maintains a strong effective parameter affecting the surface roughness followed by nose radius and the interaction $(f \times a p)$ with contributions of $50.21 \%, 20.27 \%$, and $12.69 \%$, respectively.

3. The results given by ANOVA of $\mathrm{S} / \mathrm{N}$ ratio for $(M R R)$ shows that depth of cut is the most significant with the respective contribution $54.85 \%$. The feed rate followed by cutting speed presents a statistical significance with contribution of $21.84 \%$ and $21.64 \%$, respectively.

4. The descending order of influencing machining parameters on performance characteristics which was found by ANOVA analysis were confirmed by Pareto analysis and main effects plots for S/N ratios of $(R a)$ and $(M R R)$. Effect of the interaction $(f \times a p)$ was also confirmed by $3 \mathrm{D}$ plot and contour.

5. The analysis of 2D profile and 3D topographical maps of the turned surface captured by optical platform of metrology modular Altisurf 500 has presented a great importance in the examination the effect of feed rate and nose radius of cutting tool.

6. The correlative mathematical models of $R a$ and $M R R$ are very efficient because of their higher coefficients of determination $\left(\mathrm{R}^{2}\right)$ values of $99.72 \%$ and $99.77 \%$, respectively. They have an important industrial interest, since they help to make estimations of responses without carrying out experimental runs with respect to the range intervals considered in this investigation.

7. The effectiveness of these models was verified by the normal probability plot vs. residuals and the Plot of residuals vs. run numbers. It is found that the residuals are reasonably distributed around to the straight line and do not represent any obvious pattern. The plot of estimated vs. observed values of responses are also found very close to each other.

8. The grey relational analysis was used to resolve the optimization complex problem by converting the multi-objective optimization into a single equivalent objective optimization. 
9. The single equivalent objective optimization in this analysis called grey relational grade (GRG). The highest value of this latter corresponds to the optimal levels combination of machining parameters. Therefore, the optimal levels combination for a simultaneous improvement of $R a$ and $M R R$ was obtained at; $\left(\chi r_{2} r_{3} V c_{3} f_{1} a p_{3}\right)$; major cutting edge angle of $75^{\circ}$, insert radius of $1.6 \mathrm{~mm}$, cutting speed of $440 \mathrm{~m} / \mathrm{min}$, feed of $0.08 \mathrm{~mm} / \mathrm{rev}$ and depth of cut of $0.45 \mathrm{~mm}$. The optimized responses found by the use of optimal levels selected by grey relational analysis were $(R a=$ $0.41 \mu \mathrm{m}$ and $M R R=15840 \mathrm{~mm}^{3} / \mathrm{min}$ ).

10. It is notable that there was a good agreement between the value found experimentally (0.69) and the one calculated by the estimation formula $(0.74)$. While the grey relational grade was improved from initial levels combination $\left(\chi r_{2} r_{2} V c_{2} f_{2} a p_{2}\right)$ to the optimal levels combination $\left(\alpha r_{2} r_{3} V c_{3} f_{1}\right.$ $\left.a p_{3}\right)$ by 0.13 . According to confirmation runs, the surface roughness and material removal rate were improved approximately 1.21, 0.69 times, respectively.

\section{Acknowledgments}

This work was executed in the Mechanics and Structures Research Laboratory (LMS), May 8th 1945 University of Guelma, Algeria in partnership with LaMCoS (INSA-Lyon, France). Authors would like to thank the Algerian Ministry of Higher Education and Scientific Research (MESRS) and the Delegated Ministry for Scientific Research (MDRS) for granting financial support through CNEPRU Research Project, Code: J0301520140021.

\section{References}

Asiltürk, I., \& Akkuş, H. (2011). Determining the effect of cutting parameters on surface roughness in hard turning using the Taguchi method. Measurement, 44(9), 1697-1704.

Al-Ahmari, A. M. A. (2007). Predictive machinability models for a selected hard material in turning operations. Journal of Materials Processing Technology, 190(1), 305-311.

Aouici, H., Bouchelaghem, H., Yallese, M. A., Elbah, M., \& Fnides, B. (2014). Machinability investigation in hard turning of AISI D3 cold work steel with ceramic tool using response surface methodology. The International Journal of Advanced Manufacturing Technology, 73(9-12), 17751788.

Aslan, E., Camuşcu, N., \& Birgören, B. (2007). Design optimization of cutting parameters when turning hardened AISI 4140 steel (63 HRC) with $\mathrm{Al}_{2} \mathrm{O}^{3}+$ TiCN mixed ceramic tool. Materials \& design, 28(5), 1618-1622.

Bouzid, L., Boutabba, S., Yallese, M. A., Belhadi, S., \& Girardin, F. (2014). Simultaneous optimization of surface roughness and material removal rate for turning of $\mathrm{X} 20 \mathrm{Cr} 13$ stainless steel. The International Journal of Advanced Manufacturing Technology, 74(5-8), 879-891.

Balasubramanian, S., Ganapathy, S. (2011). Grey Relational Analysis to determine optimum process parameters for Wire Electro Discharge Machining (WEDM). International Journal of Engineering Science and Technology, 3(1), 95-101.

Bouchelaghem, H., Yallese, M. A., Mabrouki, T., Amirat, A., \& Rigal, J. F. (2010). Experimental investigation and performance analyses of $\mathrm{CBN}$ insert in hard turning of cold work tool steel (D3). Machining Science and Technology, 14(4), 471-501.

Bensouilah, H., Aouici, H., Meddour, I., Yallese, M.A., Mabrouki, T., Girardin, F. (2016). Performance of coated and uncoated mixed ceramic tools in hard turning process. Measurement, 82, 1-18.

Bouzid, L., Yallese, M. A., Chaoui, K., Mabrouki, T., \& Boulanouar, L. (2015). Mathematical modeling for turning on AISI 420 stainless steel using surface response methodology. Proceedings of the Institution of Mechanical Engineers, Part B: Journal of Engineering Manufacture, 229(1), 45-61. 
Davim, J. P., \& Figueira, L. (2007a). Comparative evaluation of conventional and wiper ceramic tools on cutting forces, surface roughness, and tool wear in hard turning AISI D2 steel. Proceedings of the Institution of Mechanical Engineers, Part B: Journal of Engineering Manufacture, 221(4), 625-633.

Davim, J. P., \& Figueira, L. (2007b). Machinability evaluation in hard turning of cold work tool steel (D2) with ceramic tools using statistical techniques. Materials \& design, 28(4), 1186-1191.

Dabade, U.A. (2013). Multi-objective process Optimization to Improve Surface Integrity on Turned Surface of Al/SiCp Metal Matrix Composites Using Grey Relational Analysis. Procedia CIRP, Forty Sixth CIRP Conference on Manufacturing Systems, 7, 299 - 304.

Gaitonde, V. N., Karnik, S. R., Figueira, L., \& Davim, J. P. (2009). Analysis of machinability during hard turning of cold work tool steel (type: AISI D2). Materials and Manufacturing Processes, 24(12), 1373-1382.

Günay, M., Kaçal, A., \& Turgut, Y. (2011). Optimization of machining parameters in milling of Ti-6Al4V alloy using Taguchi method. e-Journal of New World Sciences Academy, 6(1), 1A0165.

Hassan, K., Kumar, A., \& Garg, M. P. (2012). Experimental investigation of Material removal rate in CNC turning using Taguchi method. International Journal of Engineering Research and Applications, 2(2), 1581-1590.

Hanafi, I., Khamlichi, A., Cabrera, F. M., Almansa, E., \& Jabbouri, A. (2012). Optimization of cutting conditions for sustainable machining of PEEK-CF30 using TiN tools. Journal of Cleaner Production, 33, 1-9.

Jailani, H. S., Rajadurai, A., Mohan, B., Kumar, A. S., \& Sornakumar, T. (2009). Multi-response optimisation of sintering parameters of Al-Si alloy/fly ash composite using Taguchi method and grey relational analysis. The International Journal of Advanced Manufacturing Technology, 45(3), 362369.

Kuram, E., \& Ozcelik, B. (2013). Multi-objective optimization using Taguchi based grey relational analysis for micro-milling of Al 7075 material with ball nose end mill. Measurement, 46(6), 18491864.

Karuppusami, G., \& Gandhinathan, R. (2006). Pareto analysis of critical success factors of total quality management: A literature review and analysis. The TQM magazine, 18(4), 372-385.

Lin, C. L. (2004). Use of the Taguchi method and grey relational analysis to optimize turning operations with multiple performance characteristics. Materials and manufacturing processes, 19(2), 209-220.

Lindman, H.R. (1992). Analysis of variance in experimental design. Springer-Verlag, New York, USA.

Meddour, I., Yallese, M. A., Khattabi, R., Elbah, M., \& Boulanouar, L. (2015). Investigation and modeling of cutting forces and surface roughness when hard turning of AISI 52100 steel with mixed ceramic tool: cutting conditions optimization. The International Journal of Advanced Manufacturing Technology, 77(5-8), 1387-1399.

Makadia, A. J., \& Nanavati, J. I. (2013). Optimisation of machining parameters for turning operations based on response surface methodology. Measurement, 46(4), 1521-1529.

Neseli, S., Yaldız, S., \& Türkes, E. (2011). Optimization of tool geometry parameters for turning operations based on the response surface methodology. Measurement, 44(3), 580-587.

Nalbant, M., Gökkaya, H., \& Sur, G. (2007). Application of Taguchi method in the optimization of cutting parameters for surface roughness in turning. Materials \& design, 28(4), 1379-1385.

Haq, A. N., Marimuthu, P., \& Jeyapaul, R. (2008). Multi response optimization of machining parameters of drilling $\mathrm{Al} / \mathrm{SiC}$ metal matrix composite using grey relational analysis in the Taguchi method. The International Journal of Advanced Manufacturing Technology, 37(3), 250-255.

Ross, P.J. (1996). Taguchi techniques for quality engineering. McGraw-Hill International Editions, Singapore.

Singh, D., \& Rao, P. V. (2007). A surface roughness prediction model for hard turning process. The International Journal of Advanced Manufacturing Technology, 32(11), 1115-1124.

Singh, R., \& Dureja, J.S. (2014). Comparing Taguchi method and RSM for optimizing flank wear and surface roughness during hard turning of AISI D3 steel. Proceedings of the International Conference on Research and Innovations in Mechanical Engineering, India, 139-152.

Taguchi, G. (1986). Introduction to Quality Engineering. Asian Productivity Organisation, Tokyo, Japan. 
Wang, M. Y., \& Lan, T. S. (2008). Parametric optimization on multi-objective precision turning using grey relational analysis. Information Technology Journal, 7(7), 1072-1076.

Yallese, M. A., Rigal, J. F., Chaoui, K., \& Boulanouar, L. (2005). The effects of cutting conditions on mixed ceramic and cubic boron nitride tool wear and on surface roughness during machining of X200Cr12 steel (60 HRC). Proceedings of the Institution of Mechanical Engineers, Part B: Journal of Engineering Manufacture, 219(1), 35-55.

Yallese, M. A., Boulanouar, L., \& Chaoui, K. (2004). Usinage de l'acier 100Cr6 trempé par un outil en nitrure de bore cubique. Mechanics \& Industry, 5(4), 355-368.

Zerti, O., Yallese, M.A., Belhadi, S., \& Bouzid, L. (2017a). Taguchi design of experiments for optimization and modeling of surface roughness when dry turning X210Cr12 steel. Springer International Publishing Switzerland T. Boukharouba et al. (eds.), Applied Mechanics, Behavior of Materials, and Engineering Systems, Lecture Notes in Mechanical Engineering, DOI 10.1007/978-3319-41468-3 22.

Zerti, O., Yallese, M. A., Khettabi, R., Chaoui, K., \& Mabrouki, T. (2017b). Design optimization for minimum technological parameters when dry turning of AISI D3 steel using Taguchi method. The International Journal of Advanced Manufacturing Technology, 89(5-8), 1915-1934.

Zahia, H., Athmane, Y., Lakhdar, B., \& Tarek, M. (2015). On the application of response surface methodology for predicting and optimizing surface roughness and cutting forces in hard turning by PVD coated insert. International Journal of Industrial Engineering Computations, 6(2), 267-284.

Zahia, H., Nabil, K., MA, Y., Mabrouki, T., Ouelaa, N., \& Rigal, J. F. (2013). Turning roughness model based on tool-nose displacements. Mechanics, 19(1), 112-119.

Zhang, J. Z., Chen, J. C., \& Kirby, E. D. (2007). Surface roughness optimization in an end-milling operation using the Taguchi design method. Journal of Materials Processing Technology, 184(1), 233239.

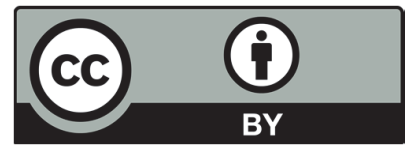

(C) 2018 by the authors; licensee Growing Science, Canada. This is an open access article distributed under the terms and conditions of the Creative Commons Attribution (CCBY) license (http://creativecommons.org/licenses/by/4.0/). 